\title{
NEW APPROACHES TO REVITALISE RURAL ECONOMIES AND COMMUNITIES - REFLECTIONS OF A POLICY ANALYST
}

\author{
Janet Dwyer ${ }^{1}$
}

Received 23 March 2016; Accepted 3 June 2016

\begin{abstract}
Looking ahead, rural Europe faces significant challenges. Some of these are longterm and will require major adaptation, such as climate change, increasing scarcity of fossil fuels and the ageing indigenous population. Others are medium-term and subject to political uncertainty, such as economic stagnation and unemployment, pressures from in-migration, and constrained public finances. Markets appear likely to continue to encourage conventional farm modernisation and capitalization, but these may increase, rather than resolve, rural problems and tensions. Seen through an ecological lens, conventional patterns of development decrease rural social, environmental and economic resilience, and yet this is becoming increasingly important. New approaches are needed which can work with global and local processes to maintain rural diversity, quality and community: key factors in resiliencebuilding. Interesting tactics may involve increasing local capacity to act, stimulating new local products, services and markets and new forms of pluri-activity. Business profitability and productivity will remain central, but can be realised in a variety of unconventional ways. Some examples and approaches are briefly presented and some general lessons identified for the new Rural Development Policy and Programmes, 2014-2020.
\end{abstract}

\section{Introduction}

At the present time, rural areas across the world are facing growing demand for a wide range of goods and services, as well as many challenges and uncertainties arising from a combination of longer-term processes associated with development and environmental capacity, and shorterterm crises and uncertainties in markets and governance.

The Economic Outlook has been examined by Piketty (2014), who takes a long-term view based upon analysis at a macro-level. After a turbulent 20th century, we are returning to a global pattern of relatively slow economic growth. Most future growth will be in the developing world, whilst in the developed world, low growth and population stasis will combine with diverging incomes (bigger gaps, rich and poor). From Piketty's analysis it can be inferred that successful economies will be those which can reduce inequalities, use resources more efficiently, and maintain wellbeing in a 'steady state'. In the developed world at least, we cannot expect simply to grow our way out of difficulties.

Projections to 2050 (FAO, 2012) suggest that global food demand will grow, but at a slower pace than it has in the previous few decades. Also, most growth in demand will be in the developing

${ }^{1}$ Professor of Rural Policy, Countryside and Community Research Institute, University of Gloucestershire, UK 
world, while that in the developed world remains relatively static. However, overlain on this pattern is a phenomenon of increasing, volatile food prices which have resulted from agri-sector policy decoupling in Europe and the increasing competition for rural resources from non-food products such as bioethanol and renewable energy installations, also water and waste storage and treatment facilities, and amenity land (public and private).

Energy prospects are also very uncertain. In the USA and EU, debt is slowing demand (USEI, 2014), whilst elsewhere, unrest \& conflict is triggering price volatility. This makes it very difficult to predict future energy prices. Climate change affects both the supply + demand of energy markets; and suggests a likely growth in renewable energy in the near future. As well as its demand for land, energy is an important input to farming and forestry: 'Energy equals $15-30 \%$ of the cost of crop production' (MGI, 2013).

Finally, it is already apparent that Climate change is occurring to a greater degree than was estimated in the first international scientific studies of the phenomenon almost 20 years ago. The ESPON CLIMATE study (2011) indicates that many rural areas of Europe will be economically, environmentally and/or socially vulnerable to negative impacts arising from global warming of at least 2 degrees centigrade by 2050. Impacts include more frequent and severe summer droughts and heatwaves, more extreme storms and flooding from coastal and inland water sources, and changes to natural populations of many species of plant and animal, as well as diseases and their vectors. Furthermore, there are potentially significant and as-yet unpredictable impacts which may arise from larger-scale shifts in weather patterns ocean currents and tidal flows.

These macro-level trends and patterns have important implications for rural areas, in many ways. It is always difficult to generalize with confidence but on the whole, it seems that increasing uncertainty could be a sustained trend, along with increasing demands upon rural land, natural resources and the knowledge and management skills of those who work with them. This implies resilience in the management and use of rural resources, in order to sustain the capacity and adaptability of rural areas (Darnhofer, 2015; Freshwater, 2015; Folke et al, 2010).

Considering these that the future emphasis of rural development should be upon achieving greater efficiency and enhanced needs more specifically: agriculture, the food sector and forest industries could work to become more resource-efficient: protecting, not wasting, and re-using resources (OECD, 2015). In parallel, the multi-functionality of rural space should be maintained and increased, to meet multiple demands (food, energy, water, fibre and construction materials, ecosystem services, leisure, health and well-being - Van Huylenbroeck et al, 2007). And rural communities must also build their resilience to cope with future shocks and uncertainties from markets, policies and biophysical changes including the greenhouse effect, continuing gradual global trade liberalization and volatility in key commodity markets (Wilding, 2011).

\section{Future options}

During the decades following the last world war, the basic foundations of modern planned and liberal governments and economies were laid. Regardless of their political and governance ideologies, both western and eastern bloc countries placed much faith in their capacity to generate continuous economic and social improvement via firms enlarging in scale, and specializing in production. This trend has been particularly marked in agriculture in many EU member states, as landscapes have been transformed from a general trend away from mixed farming towards specialist arable, permanent cropping or livestock production, of various kinds.

Today, it is probably still the case that market drivers, corporate investment and sectoral approaches to economic analysis favour this continuing move towards enlargement and specialization, for many farms and for the geographical territories in which they are situated. However, it may not be the best option when we take into account the phenomena described earlier, arising from uncertainty, instability and a need for resilience in future planning.

Contemporary economic studies suggest that in developed economies there is no strong correlation between profitability and scale of operation, in some key farm sectors. In the UK, a benchmarking exercise undertaken for the Dairy sector has noted that there is no relationship 
between herd size and business success as measured by profitability (AHDB, 2014), and work reported by Van der Ploeg in this volume (Van der Ploeg, 2016) showed that in the Netherlands, an extensive dairying approach with more diversity showed a better economic performance than a specialist high-input, high output approach, when monitored over a 10 -year period. When considering the production of fruit \& vegetables, market opportunities are a key determinant of overall profitability and these are not dependent upon high volume production: efficient use of inputs, careful attention to quality and a secure marketing outlet appear most critical. Also, in very high-value sectors such as wine production, the specificity of product characteristics means that some of the highest-earning producers have relatively low volumes of production, compared to others in the sector. In addition, many sources of guidance from agricultural extension services place emphasis upon the quality of farm management as being key to business success, rather than the scale or degree of specialization of production. However, the economies of scale phenomenon clearly still applies in cases where farms produce a relatively undifferentiated 'commodity' output, such as feed wheat, oilseeds or many kinds of meat.

Under uncertainty and in the context of the EU, very 'big' businesses as measured by farm size or numbers of livestock will include some that are particularly vulnerable or stretched; overcapitalised and managed with minimal attention to detail. Such farms can arise when families or farming companies continue to expand the scale of their operations whilst minimizing labour input and neglecting to think sufficiently about monitoring or marketing their products effectively. Such farms can also be socially isolating, as commonly one or two people work long hours in solitary conditions, also isolated because of their physical location far from centres of population and local services. Further, where the current generation of farmers suffers from a poor quality of life, the prospects of encouraging the next generation into farming can decline significantly: a problem which has been identified in some rural areas of central and southern Europe, in recent years (Zagata and Lostak, 2013).

In the current climate of uncertainty and volatility in respect of both markets and biophysical conditions, it would seem that knowledge, people-skills (being an effective communicator, listening and learning quickly), understanding markets and retaining flexibility to alter production or marketing choices, are more important than ever. For family farms in particular, this would suggest that a diversity of approach - 'not putting all the eggs in one basket' - could prove more sensible than a highly specialist one, offering a greater prospect of resilience in the longer term (Darnhofer, 2014). Economies of scope give resilience to small and micro-businesses such as family farms, as outputs can cross-subsidise each other, there may be more efficient spreading of fixed costs; and the use of labour can be spread temporally across a cycle of mixed-product activities, many of which can be highly seasonal but specific to particular types of output.

Increasing resilience could also entail giving greater attention to capturing the value-added from primary production, so that farmers receive a greater share of the total income from their products. Whilst this clearly requires additional skills and business experience, it puts the producer in more control of the process of valorization of their assets. In this context, diversification of production can be favoured by the 'efficiency of scope' of being able to offer a range of products direct to the consumer from a single, trusted source.

The recognition of these shifts in what might constitute comparative economic advantage suggest a need for farmers and policymakers in many areas of Europe to revisit and re-evaluate the traditional strategies for rural growth and development, which have placed strong emphasis upon growth, specialization and capital investment as the route to increasing the returns to farms. When facing uncertain future conditions and growing demands upon rural productive space, it may be important to aim to accommodate a greater variety of potential strategies for success than those which have hitherto dominated agricultural development.

In parallel, potential tactics for rural economic success can also be examined: should this be measured only as growth in the turnover and profits of all companies in rural areas? Currently, this approach is reflected in EU and Member State policies towards economic development, in both urban and rural settings. Growth and jobs are the most commonly used indicators for this purpose, and productivity (both physical and economic) is used as a way to indicate relative competitiveness. But when we take time to consider what aims or targets operate at the level of 
particular successful rural businesses, whether farms or service providers, it is soon apparent that many different priorities are accommodated. For a significant number of rural small and microbusinesses, the goal is not maximizing profit, but making a satisfactory return, sufficient to support the family. Bigley and Roberts (2001) argue that reliability is an increasingly critical quality and competency for organisations. And in many cases, good business is seen as a long-term concept - it has to suit the family / people involved; it needs to reward them socially and reputationally, as well as in monetary terms. And its role in giving social standing and respect is also apparent knowing you're doing something right for people or nature, or 'giving something back' to the community (Mills et al, 2014).

A number of sources suggest that resilient businesses tend to be more diversified in nature but also less resource-stretched than other businesses (e.g. Gibson and Tarrant, 2010; Darnhofer, 2014), they are thus more adaptable for their scale, and built on trusted relationships (CIPD, 2011). And resilient rural communities prioritise a high quality of life, with a range of opportunities for people to get involved and to belong - old, young, locals and incomers - through active participation, and open networks encouraging self-help and active learning. And in both the business and the social sphere, resilience carries with it a respect for the natural and cultural environment within which actors and organisations are situated: an ethic of long-term stewardship (Mills et al, 2012; Dwyer et al, 2007).

\section{Learning from experience}

So, turning to consider what kinds of rural development strategy and policy could be most helpful, in the future, we can learn from documented success stories and experiences. I will cover just a few in this discussion, in order to highlight some points about tactics and directions of travel.

'Unique Selling Points' (USPs) are widely recognized as important for small business success, in a developed economy. In a rural context, it is important for businesses and communities to think about what it is that they can offer to customers and/or residents or visitors, which is unique and special. Commonly this relates to particular local assets: for instance housing styles, historic features, local traditions and culture; the characteristic features, colours and textures of local landscapes, and the forest and farming systems that they support, as well as particular plants and animals associated with these places and spaces. In thinking about business development opportunities, local assets might lend themselves to either a diverse range of local produce, or there could be specific and distinctive items which have potential to attract custom.

To ensure that the USP of a local area can be identified and enhanced, investment in improving environmental quality for water, wildlife, woodlands may be warranted, as well as raising local awareness of environmental quality and how best to manage for this. Different environments have different but equally special character: whether coastal, hilly, remote, or peri-urban, there will be features that can be identified, strengthened and promoted.

This approach requires a greater sensitivity to the three pillars of sustainable rural development in all activities: seeking so-called 'triple bottom line' business success which simultaneously delivers for the rural economy, rural communities and the rural environment. Examples which combine USP tactics with a triple-bottom-line approach might include the following

- Linking or co-ordinating direct sales by producers and local sourcing by rural service providers, within a specific territory - this can work in respect of dairy products, vegetables, even flour/milling of locally-grown cereals, and woodfuels, in a rural development context. Successful examples exist in the UK, France, Switzerland and Germany, particularly in protected areas (e.g. the Saveurs des Parcs initiative in Switzerland; and the 'Valeurs Parcs Naturels Regionaux' mark, in France).

- Community shops / cafes / offices can operate as social enterprises, providing valuable local services as well as stimulating local economic activity and providing work opportunities for the non-mobile rural workforce (e.g. partners of farmers with small children, young people in their holidays, etc.). Many countries have experience of such successful initiatives (e.g. Social Enterprise UK, 2015; Wilkinson, 2015). 
- Soil management groups, 'minimum-tillage', and grass-fed livestock groups working to improve production quality and efficiency, as well as environmental sustainability, on farms; delivering better economic returns simultaneously with environmental benefits and within the context of collective learning structures which themselves offer social benefits to their members. Such groups are strong in the Netherlands where some now deliver collective agri-environment management, as well as in France where the government's support for 'agro-ecology' has stimulated many such collective initiatives.

- New directions for some businesses which respond to different societal needs and demands e.g. social farming and forest schools - delivering health services and therapeutic rehabilitation in a rural setting, offering new forms of engagement and different ways of valuing a business, for the farmers and foresters who successfully develop these approaches. Italy, the UK and the Netherlands all have growing social farming networks, while forest schools can also be found in many northern and Baltic Member States.

- Equitable supply chain integration, where groups of producers work in partnership with retailers, creating quality labelling/branding and targeting assured market outlets. This form of development is established in Germany, Italy, Austria and France.

- Local arts and cultural events, such as festivals, can stimulate economic activity and help develop tourism in rural areas in ways which bring significant social benefits to local people and can also offer environmental enhancement (see the LEADER example which follows).

In some of these cases, success has been linked to the ability to make hitherto unconventional connections between potential suppliers and different demands, in the modern economy. For instance, care farming, rural retreats and health walks all provide new forms of health care in rural community settings which meet a key area of demand, as the EU grapples with the challenges of an ageing population and increasing mental ill-health. Impressive examples can be found in Italy (Di lacovo et al, 2014), the Netherlands (Hassink et al, 2014) and the UK (Leck et al, 2014; Mills et al, 2015), where these initiatives are making a real difference to people with severe problems and needs. In turn, some rural entrepreneurs, including farmers themselves, can find a new vocation in these roles, giving them increased social benefits and confidence (Mills et al, ibid).

A LEADER case study emphasises the value of connections, in identifying and developing new sources of rural business and rural community success (Pays Dunois, 2016). The Beauce-Dunois LEADER group, in France, was located in a fairly intensive arable agricultural territory, and did not have a rich cultural or landscape heritage with which to develop local tourism. Nevertheless, its Local Action Group (LAG) linked with another LAG in a territory in East Germany and a third in a province in the Netherlands with which they identified shared issues of a lack of locallydistinctive assets, and shared eagerness to 'change their image'. Together, the LAGs created a 'Euro-Land-Art' festival, which is held each year in one of the three local areas. Small amounts of funding were used to commission artworks, installations and performances from a range of talented groups and individuals, and the festival was promoted to a range of local small businesses as an opportunity to showcase their products and services. The initiative proved very successful, stimulating new projects and further collaborations including between schools, artists and businesses, for more than a decade. In this case, we see almost a 'creation out of nothing' success story - except of course that these communities' unique asset was to have people who were sufficiently innovative, resourceful and enthusiastic to conceive of, and promote, this idea and then follow it through to successful realization.

\section{Discussion and suggestions for Policy}

In this range of examples, it can be seen that local people in rural areas do not have to see themselves as simply passive and vulnerable to wider market conditions and trends. Rather, the successful ventures and developments noted here work from a standpoint that markets are an 'ecosystem' of varied operators \& styles, and that buoyant rural areas can use local development processes to enrich this ecosystem with new examples. Learning from early innovators, we find that there are many simultaneously 'green' and successful businesses trading in fuels and energy, food and drink, leisure and culture and health and well-being. What these 
businesses have in common is their ability to make and maintain new links - strengthening farmer/business networks, exchanging ideas and experience, using 'triple-bottom-line' thinking. Their resilience as enterprises derives from their dynamism and flexibility: encouraging continuous improvement, and being ready to cope with unanticipated shocks.

In those ventures where producers influence supply chains, building such partnerships based on mutual respect, shared knowledge \& commitment (risk-sharing) is important. In contemporary situations, the ability to use social media gives added opportunities for learning, promoting, and securing resources such as crowd-funding.

Successful and strong rural communities work from the basis that local people often know best their needs and aspirations, but this has to be recognised and respected externally by those with whom they interact. Such communities and the initiatives that they pursue are embedded in local context and culture, using local skills, assets, capacities, and aware of local concerns. They foster joint planning and action, but also use outside knowledge and experiences to give a fresh perspective on how best to address challenges and pursue new directions. In all of this, commitment to inclusive approaches, using facilitation and outreach, is important. This should encourage open debate and discussion of priorities/choices, including recognizing conflicts among different individuals and groups so that these can be addressed and resolutions found. If funding and development decisions are made too often behind closed doors then this will engender suspicion of motives and could lead to many initiatives being undermined by lack of trust.

In conclusion, experience from many years' evaluation of rural development policies in different countries and regions suggests some lessons which are relevant to those who design and deliver these policies, as follows:

- Innovation is clearly needed, to achieve greater sustainability in rural development - plans and projects need to build for the long-term, not just supporting conventional types of change. This requires the right governance of the planning process - including all core actors, with key sources of local and expert knowledge brought together. It also requires investment to extend networks; sponsor events; offer advice; provide opportunities for businesses / communities to travel, reflect, exchange ideas together and learn from one another.

- More even risk-sharing between funding agencies and beneficiaries is often overlooked, but without it, many good project ideas will fail. Public agencies and governments need to offer certainty in the governance of rural programmes over their lifetimes, such that aids, delivery processes and knowledge (e.g. long-term staff, personal contact, transparent processes and decisions) are clear to beneficiaries. Without this, a lack of trust can easily develop, undermining funders' goals.

- Simplicity is important to encourage applicants and ensure that the best ideas come forward: this means avoiding overly 'audit-led' policies (those which place more importance on ease of control for administrators, rather than ability to deliver valuable outcomes) which can make funding bureaucratic, inflexible, and therefore inefficient. Strict rules which distort aims / outcomes should be avoided.

- If beneficiary groups can be involved in deciding HOW things are done, this can facilitate peer evaluation to discourage inappropriate or low-value applications, in the early stages of project planning. It can also help funding to reach previously excluded or underrepresented groups: inviting women, young people, the poor and the elderly to help design approaches to suit their needs can reveal hitherto un-appreciated bias in funding processes.

- In respect of administration, public authorities and delivery agencies can work to smooth spending profiles by tactics such as initially funding learning and information initiatives, and then funding project preparation, and then project outcomes: gradually building confidence with, and within, beneficiary groups. Also it is important to consider early on in 
the programme cycle, how to use funds in complementary and integrated ways, rather than in a piecemeal fashion. Finally, all those who work to promote successful funding outcomes should also take time to mark their progress, learn from their challenges and stay positive in their roles. Small procedural 'norms' can do a lot to help maintain a supportive and effective funding environment for agencies and beneficiary groups: clarifying obligations, keeping records, looking after staff, giving feedback, but also having fun and celebrating successes together.

In conclusion, sustainable and resilient rural areas and communities cannot be achieved by some kind of standard blueprint, but there are sufficient examples across Europe from which ideas and options for successful practice, and enabling policy approaches, can be drawn. Looking ahead, more emphasis is probably needed on the 'softer' aspects of these processes, investing in developing trust, good communication, mutual respect and transparent partnerships between governments, agencies, experts, communities and other beneficiary groups; from which the 'harder' outcomes can then be more reliably delivered, including accountability, reliability, good projects and significant impacts.

\section{References}

[1] Bigley, G. A. \& Roberts, K. H. (2001). The incident command system. High reliability organizing for complex and volatile task environments. Academy of Management Journal, 44(6), 1281-1299. DOI: 10.2307/3069401.

[2] Chartered Institute of Personnel Development (2011). Developing resilience: An evidencebased guide for practitioners. London: CIPD.

[3] Darnhofer, I. (2014). Resilience and why it matters for farm management. European Review of Agricultural Economics, 41(3), 461-484. DOI: 10.1093/erae/jbu012.

[4] Di lacovo, F., Moruzzo, R., Rossignoli, C. \& Scarpellini, P. (2014). Transition Management and Social Innovation in Rural Areas: Lessons from Social Farming. The Journal of $\begin{array}{llll}\text { Agricultural Education } & \text { 327-347. }\end{array}$ DOI: 10.1080/1389224X.2014.887761.

[5] Dwyer, J., Ingram, J., Mills, J., Taylor, J., Blackstock, K., Brown, K., Burton, R., Dilley, R., Matthews, K., Schwarz, G. \& Slee, R. W. (2007). Understanding and influencing positive environmental behaviour among farmers and land managers - a project for Defra by CCRU / MLURI. Department for Environment, Food and Rural Affairs, HMSO, London.

[6] ESPON CLIMATE study (2011). Climate Change and Territorial Effects on Regions and Local Economies. Applied Research 2013/1/4. Final Report | Version 31/5/2011 Main Report. Retrieved from:

https://www.espon.eu/export/sites/default/Documents/Projects/AppliedResearch/CLIMATE/ ESPON_Climate_Final_Report-Part_B-MainReport.pdf.

[7] Food and Agriculture Organisation (2012). World agriculture towards 2030/2050: the 2012 revision. Nikos Alexandratos and Jelle Bruinsma, Global Perspective Studies Team. ESA Working Paper No. 12-03, June 2012. Agricultural Development Economics Division, Food and Agriculture Organization of the United Nations. Also: www.fao.org/worldfoodsituation/wfs-home/foodpricesindex/en.

[8] Freshwater, D. (2015). Vulnerability and Resilience, two dimensions of rurality. Sociologia Ruralis, 55(4), 497-515. DOI: 10.1111/soru.12090.

[9] Folke, C., Carpenter, S., Walker, B. H., Scheffer, M., Chapin, T. \& Rockström, J, (2010). Resilience Thinking: Integrating Resilience, Adaptability and Transformability. Ecology and Society 15(4), art. 20.

[10] Gibson, C. A. \& Tarrant, M. (2010). A 'Conceptual Models' Approach to Organisational Resilience. Australian Journal of Emergency Management._25(2), 6-12. 
[11] Hassink, J. Hulsink, W. \& Grin, J. (2014). Farming with care: the evolution of care farming in the Netherlands. NJAS Wageningen Journal of Life Sciences. 68, 1-11. DOI: 10.1016/j.njas.2013.11.001.

[12] Leck, C., Evans, N. \& Upton, D. (2014). Agriculture - Who cares? An investigation of 'care farming' in the UK. Journal of Rural Studies. 34, 313-325. DOI: 10.1016/j.jrurstud.2014.01.012.

[13] Mills, J., Lewis, N. \& Dwyer, J. (2010). Unpacking the Benefits of LEAF Membership: a qualitative study to understand the added value that LEAF brings to its farmer members. Stoneleigh: LEAF.

[14] Mills, J., Taylor, J., Dwyer, J. \& Bartlett, J. (2015). The well-being benefits of sensory-rich farm visits. International Journal of Agricultural Management 10/2014; 4(1), 3-10. DOI: 10.5836/ijam/2014-01-02.

[15] OECD (2015): Agriculture and Climate Change. September 2015, OECD Paris. Available at: http://www.oecd.org/tad/sustainable-agriculture/agriculture-climate-change-september2015.pdf.

[16] Pays Dunois (2016). Description of the Euro-land-art initiative. Retrieved from: http://www.pays-dunois.fr/index.php/euro-land-art/le-concept.

[17] Piketty, T. (2014). Capital in the twenty-first century. Cambridge, MA: Harvard University Press.

[18] Social Enterprise UK (2015). The State of Social Enterprises survey, UK. DTP, UK. Retrieved from:

http://socialenterprise.org.uk/uploads/editor/files/Publications/FINALVERSIONStateofSocial EnterpriseReport2015.pdf.

[19] Van Huylenbroeck, G., Vandermeulen, V., Mettepenningen, E. \& Verspecht, A. (2007). Multifunctionality of Agriculture: A Review of Definitions, Evidence and Instruments. Living Reviews in Landscape Research 1(3).

[20] Wilding, N. (2011). Exploring Community Resilience. UK Carnegie Trust. at http://www.carnegieuktrust.org.uk/getattachment/75a9e0c4-8d75-4acb-afac-

6b1cbd6f2c1e/Exploring-Community-Resilience.aspx.

[21] Wilkinson, C. (2015). A map of social enterprises and their ecosystems in Europe: synthesis report. Directorate-General for Employment, Social Affairs and Inclusion. Brussels: Commission of the European Communities.

[22] Zagata, L. \& Lošták, M. (2013). Farming Models for Young Farmers and New Entrants in Europe. Part of Farming Transitions: Pathways Towards Regional Sustainability of Agriculture in Europe (FP7 KBBE 2010-4) WP4 Deliverable 4.1 FINAL REPORT 31.3.2013. Praha: Czech University of Life Sciences. 